\title{
Erratum to: Constraints on oceanic meridional heat transport from combined measurements of oxygen and carbon
}

\author{
L. Resplandy 1 (1) R. F. Keeling ${ }^{1} \cdot$ B. B. Stephens ${ }^{2} \cdot$ J. D. Bent ${ }^{2} \cdot$ A. Jacobson ${ }^{3}$. \\ C. Rödenbeck ${ }^{4} \cdot$ S. Khatiwala ${ }^{5}$
}

Published online: 19 August 2017

(C) Springer-Verlag GmbH Germany 2017

\section{Erratum to: Clim Dyn (2016) 47:3335-3357 DOI:10.1007/s00382-016-3029-3}

The original article has been published online with 2 errors. The errors have been corrected as below:

1. The definition of pre-industrial oceanic potential oxygen $\left(\mathrm{OPO}_{\mathrm{pi}}\right)$ given in Eq. (7) reads:

$$
\mathrm{OPO}_{\mathrm{pi}}=\mathrm{O}_{2}{ }^{*}+1.1 \times \mathrm{C}_{\mathrm{pi}}{ }^{*}
$$

but should appear as:

$\mathrm{OPO}_{\mathrm{pi}}=\mathrm{O}_{2}{ }^{*}+1.1 \times \mathrm{C}_{\mathrm{pi}}{ }^{*}-\left(1 / \mathrm{X}_{\mathrm{N}_{2}}\right) \times \mathrm{N}_{2}$

where $\mathrm{O}_{2}{ }^{*}$ and $\mathrm{C}_{\mathrm{pi}}{ }^{*}$ are the quasi-conservative ocean tracer concentrations tracking air-sea exchanges of $\mathrm{O}_{2}$ and pre-industrial $\mathrm{CO}_{2}, \mathrm{~N}_{2}$ is the dissolved $\mathrm{N}_{2}$ ocean concentration and $\mathrm{X}_{\mathrm{N}_{2}}$ is the atmospheric mole fraction of $\mathrm{N}_{2}$ $\left(\mathrm{X}_{\mathrm{N}_{2}}=0.7808\right)$.

The online version of the original article can be found under doi:10.1007/s00382-016-3029-3.

L. Resplandy

lresplandy@ucsd.edu

1 Scripps Institution of Oceanography, University of California, San Diego, La Jolla, CA, USA

2 National Center for Atmospheric Research, Boulder, Colorado, USA

3 Earth System Research Laboratory, NOAA, Boulder, Colorado, USA

4 Max Planck Institute for Biogeochemistry, Jena, Germany

5 Department of Earth Sciences, University of Oxford, Oxford OX1 3AN, UK
This definition of $\mathrm{OPO}_{\mathrm{pi}}$ and the $\mathrm{OPO}_{\mathrm{pi}}$ data shown on Fig. 1 therefore include the changes in OPO due to air-sea fluxes of $\mathrm{O}_{2}$ and pre-industrial $\mathrm{CO}_{2}$ but also due to the thermally driven air-sea fluxes of $\mathrm{N}_{2}$, which are important for understanding changes in pre-industrial atmospheric potential oxygen $\left(\mathrm{APO}_{\mathrm{pi}}\right)$. Including the $\mathrm{N}_{2}$ contribution makes $\mathrm{OPO}_{\mathrm{pi}}$ a mirror tracer of $\mathrm{APO}_{\mathrm{pi}}$ across the air-sea interface, i.e. with equivalent air-sea fluxes. The data based $\mathrm{OPO}_{\mathrm{pi}}$ to potential temperature ratio derived from Fig. 1 includes the $\mathrm{N}_{2}$ contribution and is equal to $-3.9 \mathrm{nmol} / \mathrm{J}$. Note that without the $\mathrm{N}_{2}$ contribution, this ratio would equal $-4.4 \mathrm{nmol} / \mathrm{J}$.

2. In Table 1, the isopycnal defining the base of the thermocline reads $\sigma_{\theta}=24.7$ and should read $\sigma_{\theta}=27.4$.

Acknowledgements We thank Gregory de Souza for identifying the typo in Table 1 of Resplandy et al. (2016).

\section{Reference}

Resplandy L, Keeling RF, Stephens BB, Bent JD, Jacobson A, Rödenbeck C, Khatiwala S (2016) Constraints on oceanic meridional heat transport from combined measurements of oxygen and carbon. Clim Dyn. doi:10.1007/s00382-016-3029-3 